\title{
Correction of McAdams, D. P., Trzesniewski, K., Lilgendahl, J., Benet-Martinez, V., \& Robins, R. W. (2021). Self and Identity in Personality Psychology
}

In the published version of

McAdams, D. P., Trzesniewski, K., Lilgendahl, J., Benet-Martinez, V., \& Robins, R. W. (2021). Self and identity in personality psychology. Personality Science, 2, Article e6035. https://doi.org/10.5964/ps.6035

only one affiliation of Verónica Benet-Martínez was included by error. Her second affiliation was not added to the published version, but should have been added because it contributed equally to her work. The details for the second affiliation are:

Catalan Institution for Research and Advanced Studies (ICREA), Barcelona, Spain

\section{eapp}

Personality Science (PS) is an official journal of the European Association of Personality Psychology (EAPP).
(1) leibniz-psychology.org

PsychOpen GOLD is a publishing service by Leibniz Institute for Psychology (ZPID), Germany. 